\title{
Toward understanding three phases of individual responses to paradox
}

by

Gunnar Birkelund, Associate Professor, School of Business and Economics

UiT The Arctic University of Norway, E-mail: gunnar.birkelund@uit.no.

The article is published in the Baltic journal of management. You can download the published version by following this link: https://doi.org/10.1108/BJM-05-2021-0178.

Emerald allows authors to deposit their AAM under the Creative Commons Attribution Noncommercial International Licence 4.0 (CC BY-NC 4.0). To do this, the deposit must clearly state that the AAM is deposited under this licence and that any reuse is allowed in accordance with the terms outlined by the licence. To reuse the AAM for commercial purposes, permission should be sought by contacting permissions@emeraldinsight.com. 


\begin{abstract}
Purpose - To further paradox research at the individual level through applying a framework of three phases of individual response to paradox — recognition, understanding and behaviour.
\end{abstract}

Design/methodology/approach - Critical and integrative review of previous studies of individual responses to paradox.

Findings - The role of individual understanding is limited in extant research on individual responses to paradox. Individual understanding tends to be equated with behaviour, and thus knowledge of understanding is not differentiated enough, neither is the link between understanding and behaviour sufficiently developed.

Originality/value - The review contributes to paradox theory by separating individual understanding and then providing a framework in which recognition, understanding and behaviour can be reintegrated in new ways. In addition to more accurate discernment of individual understanding, and of combinations of responses across phases, the three-phase framework facilitates investigation of more intricate influences across phases and paths of evolution of such responses over time.

Research limitations/implications - The review does not consider the relationship to interactional, organisational and environmental contexts. The recommendation for future research is to explore individual responses to paradox more entirely, to provide an adequate ground for extending paradox theory across individual and broader levels of analysis.

\title{
Key words
}

Paradox, tension, duality, contradiction, dialectic, individual responses 


\section{Introduction}

Individuals' interpretations of and behavioural responses to paradox are key to effective organisational behaviour (Smith and Lewis, 2011). Although the overall focus of management and organisation research has been on the organisational processes of paradox (Miron-Spektor et al., 2018; Schad et al., 2016), the literature demonstrates many ways that individuals respond to paradox, defined as 'persistent contradiction between interdependent opposites' (Schad et al., 2016; Smith and Lewis, 2011). If individuals recognise both opposites of paradox, this can lead to an understanding of the interwoven nature of opposites and the search for creative both/and strategies for behaviour (Miron-Spektor et al., 2018). Contrariwise, the denial of paradox, often spurred by anxiety, can result in a lack of understanding and paralysis rather than constructive behaviour (Lewis, 2000). While some individuals vacillate between separate opposites, or perceive dilemmas that require trade-offs, others are able to reframe the paradox and develop 'workable certainties' that enable useful behaviour (Lüscher and Lewis, 2008). Some understand the paradox in an integrated way, and recent research evidences several useful behavioural responses.

However, when studying individual responses within an overall frame of explaining organisational processes, in which the efficacy of individual behaviour counts for much, paradox research tends to simplify individual responses. Responses may be assigned to broad either/or and both/and categories and then treated alike. Different ways of understanding paradox may be ignored, and overall responses that cut across behaviour and understanding (Barge et al., 2008; Cuganesan, 2017; Gibbs, 2009; Knight and Paroutis, 2017) may incubate a tendency to affix each category of behaviour to a particular understanding of paradox (Fagerlin and Wang, 2021; Papachroni et al., 2016). Researchers observe salient behaviour and may relate it to an inferred cognitive underpinning (e.g., Andriopoulos and Lewis, 2009; Cuganesan, 2017; Smith, 2014; Smith and Besharov, 2017) rather than to an understanding 
based upon focused interviews (e.g., Fredberg, 2014; Gibbs, 2009; Stadtler and Van Wassenhove, 2016; Tracy, 2004). More advanced understanding than is really justified tends to be read into behaviour that engages both opposites of paradox (Bednarek et al., 2017).

This bias towards salient process behaviour and oversimplification of underlying understanding privileges some managers over their employees. Managers' understanding of paradox is often overrated, while others are unduly depicted as depending on them for the amendment of denial and tensions that tear paradox apart.

The purpose of this review is to examine research on individuals' responses to paradox with a focus on their understanding and thus potential for behaviour, so that enhanced knowledge of individuals' responses to paradox can inform interactional and organisational models of paradox management. Future research should recognise individuals' development of understanding, past recognition of paradox (Child, 2020; Lüscher and Lewis, 2008) and as a basis for differing behaviours over time (Smets et al., 2015; Stadtler and Van Wassenhove, 2016). To pave the way for accomplishing this aim, the review synthesises a variety of previous studies to better discern individual understanding and full cross-phase response. This may enable research on more intricate individual responses and on their possible contribution to organisational effectiveness.

The remainder of the review proceeds as follows. First, the approach and the method of review are introduced. Then, several studies are drawn on to abridge individual responses in the three phases of recognition, understanding and behaviour. Abridged responses are positioned vis-à-vis each other according to their complexity. Finally, patterns of response across the three phases are considered, and possible implications are noted for further research on individuals dealing with paradox. 


\section{Approaching individual responses to paradox}

This review differs from other studies focusing on individual responses to paradox. The term individual 'responses' refers to particular outcomes that result in each of the phases in which individuals respond to paradox. In the literature, the term is sometimes used in a broader sense, to refer to individuals' general approach to addressing paradox or to the overall process of individual response (e.g., to the perspective of Miron-Spektor et al., 2018). Individual 'understanding' is thus more specific than the paradox mindset, which is a predisposition to the whole process. It refers to frames within which paradox is located in order to be understood, such as selection, prioritisation and synthesis, which result in the (first and) second phase of responding to paradox (Figure 1). More advanced frames may emerge from a more complex secondary sensemaking process (Child, 2020) that occur in the second phase, and which may extend into the third phase that begins with making sense of how to act in the present context. The understanding of paradox remains within the individual, over time perhaps as a repertoire of understandings and approaches to future behaviour.

Insert Figure 1 about here

The simple framework in Figure 1 may serve to illustrate how this review focuses on individual responses (and disregards processes and contexts) to open up individual response for novel conceptualisation. The focus is on straightforward outputs, but these outputs may often be simplified and neglected, and the relationship between outputs of different phases can be more complex than recognised in present research. Paradox theory gives ample opportunity to move rather swiftly from recognition to behaviour (e.g., Pradies et al., in press). According to a prevalent explanation, anxiety related emotions and defensive reactions lead to avoiding and eliminating the tensions of paradox, whereas calmness, 
comfort and enthusiasm lead to engagement, useful understanding and creative behaviour. Examining the findings from varied studies of individual responses to paradox, this review aims to expose the outcomes following initial emotions and ending in actual behaviour.

The approaches to sensemaking and action shall include more emotions, motivations to cooperate with opposite parties, and inclinations towards understanding paradox. Some individuals enter the second phase, in which they adopt or develop new understanding of a recognised paradox. Sometimes an understanding regarded as satisfactory is adopted by recognition, e.g., when a particular understanding of paradox becomes salient in the organisational process, or it is already possessed when recognising paradox. At other times, an individual must learn about the paradox before it is sufficiently understood, particularly in the case of an unfamiliar paradox. With familiar paradoxes, perhaps surfaced in different versions over time, individuals could have learned several frames for understanding. For example, the perceived balance between opposites, or the existence of links between them, may vary depending on the organisational context in question.

Some knowledgeable individuals may start the behavioural phase with consideration of if and how to act in different behavioural contexts. In developing their intention to act, and their choice of actions, reflections could involve resources they could mobilise, impediments, power inequalities and expected consequences of different actions. Regardless of the complexity of their understanding, they can choose between many behaviours from avoiding a paradox altogether to complexly accommodating all opposites of paradox. Understanding is therefore distinguished as a phase in responding to paradox, with its own categories of response that can be diversely related to behavioural responses.

The definition of paradox allows a review of diverse individual responses to different kinds of paradox. Paradox may be both objectively real and socially constructed, and as contingencies may muddle the social manifestation as well as the individual experience of 
paradox (Berti and Simpson, in press; Hahn and Knight, in press), the central characteristics of contradiction and interdependency may sometimes remain potentials rather than being continuously present. Furthermore, if you favour interdependency (i.e., that oppositions are interlinked such that they maintain each other) over contradiction (i.e., that oppositions are difficult to maintain simultaneously and might even be mutually exclusive), a presumption that both/and responses to paradox are more effective than either/or responses may result (Cunha and Putnam, 2019). In this review, interdependency and contradictoriness are regarded as equally important in general but may vary for different kinds of paradox and for a particular paradox over time. Rather than focusing on whether a response accepts both (at least practical/functional) interdependency and (at least apparent) contradictoriness, it is more important to discern the different qualities of interdependency and contradictoriness manifesting in individuals' responses and to assess the consequences of responses empirically.

\section{Method of review}

Although this is an integrative and critical review (Alvesson and Sandberg, 2020; Elsbach and van Knippenberg, 2020), and not a structured literature review, it followed usual steps adopted by other reviews. To identify new articles to be added to the collection of literature on the topic from books and main journals in organisation and management, and their reference lists, since the late 1980s, Web of Science and Google Scholar were searched using the terms paradox, contradiction, dialectic and tension. Abstracts and contents were scanned to include articles that treated paradox as a focal topic, explained phenomena of interest for organisations and focused on individual responses. Thus, articles were excluded if they focused on broader or more organisational responses (e.g., Jarzabkowski et al., 2013; MironSpektor et al., 2018), unfortunately reducing the input on behavioural responses. New articles were added during reviews. No cut in terms of journal impact factor was used. Uncountable 
articles were scanned, and a reasonably comprehensive and diverse set of articles was selected for review (Table 1).

Insert Table 1 about here

The review brought together observations of the responses of different types of individuals, such as managers at different levels, employees, creatives and organisational scholars, and examined their responses to different kinds of paradox. The intention was not to compare responses to judge individuals. The resources that low-level employees have for agency and engagement of paradox are less than those of managers (Berti and Simpson, in press). However, managers also face scarcity of resources, such as finance and time, which may spur the recognition of paradox but impede the exploration of alternative ways to understand it (Miron-Spektor et al., 2018). Examining the observations of different types of individuals set the stage for being critical of the assumptions of different streams of paradox research, and it opened up the possibility to improve discrimination of responses by comparison with a wider selection of observations.

At this stage, familiarisation with the literature had bred an awareness of a sensemaking phase that often seemed to be lacking in empirical research. Rather than dwelling upon how assumptions and traditions had led to the lack, the decision was made to facilitate improvement in further research. The next step was to analyse the observations of individual responses and to integrate them within a common framework to serve this aspiration. Responses were abridged in each of the three phases, outlining typical responses that are not novel or nuanced, but making up a comparison base that future research could use to improve discrimination of responses. After examining the responses within each phase, relationships of responses across the three phases were considered. Previous observations of 
responses were mapped, taking notice of patterns, and finally, overlooked possibilities were pointed out with a critical view to the oversimplification of individual understanding and cross-phase relationships. The guiding assumption of review was that the critical attitude could be carried out by analysing concrete findings, rather than by examining the literature at a deeper level, and that the result would expose field developments that could be interpreted to build a platform for improving future research.

\section{Responses in the framework of three phases}

Individual responses were characterised, grouped and abridged by two analytical dimensions. The first was the well-known extent to which responses include both (all) opposites of paradox. For example, if individuals deny the presence of an opposite, do not want to understand it, or misrepresent it in communication, they reduce the paradox towards a single opposite or dissolve it. Contrariwise, individuals may accept and accommodate the opposites. The second dimension pertains to the complexity of responses too, but it differ for each phase.

As regards recognition, the extent of assuming responsibility for understanding and dealing with the paradox together with other parties characterises responses. Empirical studies demonstrate that individuals differ in taking responsibility for dealing with paradox (Baxter and Montgomery, 1996; Child, 2020; Fredberg, 2014; Stohl and Cheney, 2001), which reduces their motivation for accommodating each other's needs and understanding the paradox sufficiently well (Lüscher and Lewis, 2008; Sharma and Bansal, 2017). For characterising different ways to understand paradox, the review takes a closer look at the extent to which individuals integrate opposites. Opposites can be integrated in several ways parallel to scholars' notions of interdependency—from complicated interplay between basically independent and self-contained opposites, via interrelated opposites with mutual 
influences and complements, to fully interdependent and unified opposites that implicate each other and constitute whole entities (Baxter and Montgomery, 1996; Chen, 2002; Lewis, 2000; Schad et al., 2016; Smith and Berg, 1987). Cognitive complexity theory posits that some individuals integrate paradox through frames in which each opposite has multiple attributes and there are several conflicting, reinforcing and neutral relationships between the opposites (Hahn et al., 2014, p. 467). However, most empirical studies are ambiguous and virtually none explain how individuals conceive of complex relationships between opposites.

Behavioural responses were analysed according to the extent to which they allow each stakeholder to the opposites to participate in negotiating mutually effective behaviour. This may further the concern with the effectiveness of responses, which is ubiquitous in present research. Because inviting such stakeholder collaboration may contribute to effective consequences (that are themselves outside the scope of this review), developing this characteristic may facilitate the empirical investigation of if and how behavioural responses result in effective consequences.

A possible misunderstanding is that the three phases suggest a rational person moving through separate stages in a linear manner. However, responses are closely connected across the phases, and neither clear boundaries nor a certain sequence between the phases is assumed (although some recognition is necessary for understanding to occur). It should also be noticed that drawing on diverse studies and distinguishing cognitive and behavioural responses escalate the problem of conflation of terms in this field. Nevertheless, the need for conversation is addressed by clarifying (rather than endlessly discussing) terms of responses.

\section{Recognition of paradox}

In the first phase, individuals need to recognise that opposites exist simultaneously within the context in question and that sufficiently understanding the resulting paradox is required for 
effective and responsible behaviour. The lack of such acceptance is often regarded as a problem, because it involves neglecting important parts, relationships or patterns of a complex and dynamic world, which may result in less than effective and responsible behaviour (Lewis, 2000; Seo et al., 2004). Instead of accepting paradox, individuals sometimes respond with denial when experiencing it or sensing that it may be encountered.

Denial is the conscious or unconscious refusal to recognise paradox, whether it stems from one or more oppositions or from a combination of oppositions (Peng and Nisbett, 1999; Seo et al., 2004). Because individuals sometimes experience discomfort and anxiety-related emotions in the presence of paradox, they tend to deny paradox through unconscious defence mechanisms, such as splitting (dividing and polarising internal opposites) and projection (transferring perceived negative qualities outwards to a third person) (Lewis, 2000; Smith and Berg, 1987). Such defensive denial is the focus of psychodynamics and is dysfunctional in light of the context (see also the 'double-bind' theory of communication (Tracy, 2004)). However, denial may be useful when paradox is not sufficiently relevant or important. Furthermore, the context may contain satisfactory clues for 'priming' appropriate actions from individuals not recognising paradox (El-Sawad et al., 2004).

Intermediate positions between denial and full recognition of paradox have been observed. By neglect, individuals are aware of paradox without accepting any consequent responsibility for understanding and dealing with it. For example, they may not take a particular paradox seriously (Stohl and Cheney, 2001), pay scant attention to a potential problem (Child, 2020; Pradies et al., in press) or use a negative lens that renders awareness passive (Baxter and Montgomery, 1996). Disorientation refers to the misrepresentation of one or more opposites, and, thus, less awareness of the full paradox. For example, managers may transmute the basic profit vs. people contradiction into more superficial conflicts within which workers are disempowered (Berti and Simpson, in press; Fairhurst et al., 2002). 
Professional women may renounce the authority of femininity to succeed in organisations (Wood and Conrad, 1983). Resistance comes out as awareness of the full paradox with an inclination to support one side without acceding to the contradictory opposites. Individuals may find that the other opposites do not serve their interests, or they may believe in or be committed to particular assumptions or an ideology that defies them (Hargrave and Van de Ven, 2017). Resistance and disorientation typically reduce the responsibility for understanding paradox and taking common action.

Managers may both welcome opposites and partake in responsibility for dealing with them, yet sometimes without any need to understand the resulting paradox in a complex manner (e.g., Beech et al., 2004; Fredberg, 2014). We may distinguish between such embracement and acceptance, whereby individuals, in addition to situating the oppositions within a frame that allows some type of simultaneous presence, acknowledge that understanding the paradox is key to effective and responsible action with regard to all parties (Lüscher and Lewis, 2008; Smith and Tushman, 2005).

Individuals may move from denial to awareness and different motivations by encountering a paradox again. Sometimes this involves the adoption or development of new understanding through interaction with the next phase. In any case, the move towards acceptance is facilitated by emotional equanimity (Smith and Lewis, 2011), a mindset valuing paradox (Miron-Spektor et al., 2018) or cognitive complexity, i.e., cognitive frames and processes that allow paradox in the domain in question (Smith and Tushman, 2005). Developmental theory posits that mature adults are cognitively complex in many domains, they continually identify new opposites and attempt to understand paradoxes (Bartunek et al., 1983). An experienced individual may, thus, accept and complexly understand many paradoxes, without always being conscious about it or making it known to others. 


\section{Understanding of paradox}

The simplest of the approaches that may be adopted or developed to understand a paradox is selection, i.e., the deliberate choice of one opposite to the exclusion of others (Seo et al., 2004). For example, one opposite is believed whereas another is rejected as false (which may lead to denial in the future). Separation is the continuance of opposites in such a way that they are divided into different contexts. Each oppositional tendency applies validly to different time periods or social spaces, such as departments, levels and teams, or is attributed to different people or units (e.g., Poole and Van de Ven, 1989; Tracy, 2004). Selection and separation may sometimes result from better knowledge of opposites but are often errors because the opposites genuinely coexist within the same context. Over larger spans of time and space, separation could be combined with prioritisation, which allows opposites to coexist in some order of precedence and subordination, or balance, which maintains an equal relationship between coexisting opposites (Canibano, 2019; Mickel and Dallimore, 2009; Sirris, 2019; Tracy, 2004).

In the last approaches, individuals still separate opposites that tend to be pitted against each other simultaneously with attempts to reduce tensions. When more sophisticated approaches emerge, individuals uphold such tensions to facilitate exploration of and reflection on the relationship among opposites (Bartunek et al., 2000; Lewis, 2000). They may seek to integrate opposites by including them within a common or higher-level frame and perhaps starting to link them (Bednarek et al., 2017; Canibano, 2019; Carollo and Guerci, 2018; Sirris, 2019; Stadtler and Van Wassenhove, 2016). An outside frame could emerge from reflections on underlying assumptions and more complete contexts and facilitate the integration of opposites.

Some empirical studies have observed simple complementarity, in which individuals appreciate one opposite as the means for achieving another opposite (Fagerlin and Wang, 
2021; Lüscher and Lewis, 2008; Papachroni et al., 2016; Tracy, 2004). For example, operational staff construes innovation as a tool for improving the efficiency of the existing business (Papachroni et al., 2016). More complexity is involved when opposites are creatively merged in synthesis (Baxter and Montgomery, 1996; Seo et al., 2004; Stohl and Cheney, 2001). As an example, leadership can be regarded as the facilitation of more real participation and even as the dissolution of itself (Stohl and Cheney, 2001). Unfortunately, the opposites in synthesis come to be confounded because some opposites are privileged over others and premises are violated. The term transcendence could be reserved for a more complete reframing of the opposites and/or their relationships, in which the original opposites are maintained simultaneously with the subsidence of harmful tension between them. For example, individuals could connect the attributes of oppositions in new ways or with new or redefined attributes so that the original oppositions occur as minor ones within a larger paradox (Wood and Conrad, 1983) or as integral parts of a new whole (Hahn and Knight, in press; see also Poole \& Van de Ven, 1989).

\section{Behaviour regarding paradox}

In the third phase, individuals act in or with the paradoxical situation — whether they recognise and understand the paradox or not. The behavioural responses sometimes had to be loosened from understanding and be redefined in purely behavioural terms.

The simplest of the observed behaviours regarding paradox are avoidance, i.e., lack of behaviour related to paradox, and adherence, i.e., behaviour in accordance with one opposite instead of another. If individuals do not yet recognise or understand paradox, they may feel unable to take action because all consequences seem negative (Lewis, 2000). Yet, with a well-developed understanding, individuals may attempt to by-pass difficult social tensions (Stadtler and Van Wassenhove, 2016). Adherence may seem to be due to denial but really 
occurs because of (or together with) active selection and prioritisation (see also Pache and Santos, 2013). By vacillation, individuals switch between behaviours, sometimes adapting to one (mix of) opposite(s) and sometimes to another (Tracy, 2004). Vacillation can occur unreflectively, as a result of denial and shifts of attention between opposites, which tends to increase tensions. However, vacillation can also be a reflective strategy, based on a more or less integrated understanding, for adapting to the demands of different social contexts (e.g., Smith, 2014). Reflective vacillation may situationally privilege an opposite without building up tension (Smets et al., 2015; Stadtler and Van Wassenhove, 2016), and it certainly tends to do so when stakeholders to opposites can take part in enacting mutually effective behaviours.

More affirmative is living with paradox, which comprises flexible behaviour to thrive on, rather than to work against, paradox (Bartunek et al., 2000; Baxter and Montgomery, 1996; Beech et al., 2004; Murnighan and Conlon, 1991). Effective managers possess the ability to act flexibly and appropriately from a well-developed repertoire of behaviours (Denison et al., 1995), which may or may not require advanced understanding of paradox. In any case, it is essential to acknowledge opposites for participants and stakeholders who might become concerned by less affirmative actions (Cuganesan, 2017; Fredberg, 2014; Pamphile, in press). In contrast, advocacy involves promotion, bargaining or political tactics to achieve goals associated with one (or few) opposite(s) of paradox (Cuganesan, 2017; Di Domenico, 2015; Hargrave and Van de Ven, 2017; Solebello et al., 2016). Variations in advocacy may depend on the relative power of parties to the opposites, the degree of antagonism between parties and their commitment to maintain or change this relationship, but opposite parties are not necessarily invited to participate in identifying effective behaviour.

To acknowledge paradox, managers may wish to communicate oppositions explicitly albeit not in their fullness or with their potentially hostile relationships, which may provide common benefits such as a shared identity and eased social tensions (Andriopoulos and 
Lewis, 2009; Berglund et al., 2004; Fagerlin and Wang, 2021; Kan and Parry, 2004; Smith and Besharov, 2017; Stohl and Cheney, 2001). We can label this communication strategy as including paradox in a bounded way. Various tactics can be used, such as irony, preparation, rhetoric and ambiguity (Barge et al., 2008; Bednarek et al., 2017; Fiol, 2002; Gibbs, 2009; Hoelscher, 2019; Vermaak, 2012). With symbolic integration, the sender of a message uses complex symbols to 'respond fully to all opposing forces at once without any compromise or dilution' (Baxter and Montgomery, 1996, p. 65). It may enable mutual respect and complex adaptation, but idealistic ambiguity may also permit recipients to advocate their own views. An interesting possibility is to introduce complex symbols to transcend the present understanding of paradox, such as when the US President Lyndon Johnson redefined the contradiction between segregation and non-discrimination; the real contradiction to discrimination is actively providing all people with equal opportunity (Wood and Conrad, 1983).

Balancing practices refers to the implementation of practical solutions and routines that accommodate the oppositions of paradox. For example, managers establish organisational solutions within which both exploration and exploitation can be pursued (Knight and Harvey, 2015; Papachroni et al., 2016), and lower-level employees adapt local practices for coping with oppositions such as customer orientation in opposition to organisational interests (McNamee and Peterson, 2014; Smets et al., 2015; Zimmermann et $a l ., 2018)$. It may be based on a sophisticated understanding of a paradox as well as of the situation beyond the paradox itself (Eisenhardt et al., 2010). Shaping the context brings about social processes, systems and forums in which paradoxes can be recognised, discussed and reflected upon (Calabretta et al., 2017; Knight and Paroutis, 2017; Putnam et al., 2016; Vallaster et al., 2021). Beyond contributing to a favourable context for others to address paradox, this category involves more systematic measures for enabling individuals to be 
aware of and develop complex understanding of paradoxes. Shaping the context can facilitate broad participation in negotiating responses to paradox, while balancing practices may suffer more from impeding participation from distant stakeholders.

\section{Summary and implications for future research}

Figure 2 summarises the abridged individual responses to paradox within each phase, and Table 2 adds patterns of responses observed across the phases. Although paradox research at the individual level shows several and quite different responses, increased differentiation would be useful. In particular, differentiation of ways in which individuals integrate paradox is often missing. Some studies in the first group of Table 2 also tend to neglect understanding altogether, by linking behaviour to an undeveloped frame of recognition. In the second group of Table 2, responses tend to be observed at the same level of complexity across understanding and behaviour, partly aside for an undifferentiated understanding beyond balance. However, responses at the same level of complexity across the phases should not be an assumption of paradox theory.

Insert Figure 2 and Table 2 about here

A few studies in the third group of Table 2 observe that the habitual attribution of denial or lack of understanding to explain adherence and avoidance could involve a serious bias. Adherence could be based on situational prioritisation, such as momentarily giving in to authoritarian superiors (Aoki, 2020), or be modified to oppose upper management (Olsen and Solstad, 2020). Avoidance could be chosen to secure undisturbed communication or to resist oppressive relationships (Ban, 2017; Hoelscher, 2019; Howard and Geist, 1995; Jian, 2007; Tuckermann, 2019). Different theoretical perspectives suggest alternative individual 
understandings, and as often as not, a closer empirical investigation would be required for valid interpretation.

This review contributes to paradox theory by bringing together a variety of studies of individual responses to paradox and examining their different observations. More specifically, the review distinguishes individual understanding as a separate phase, and it provides a three-phase framework in which recognition, understanding and behaviour can be more accurately identified and reintegrated.

In future research, new observations could be compared with the abridged responses when individual responses are identified. To allow more accurate identification, the review argues that individual responses should be observed in themselves initially (i.e., not in connection with probable consequences and theoretical perspectives), before they are interpreted in their full context. Closer observations, which are particularly needed of the ways in which individuals understand paradox, should thus result in the identification of more accurate, varied and novel individual responses to paradox. For example, some individuals may understand the situation such that they attempt to evoke opposing views and complex co-operation through essentially one-sided behaviour (Cuganesan, 2017; Vermaak, 2012). Not only does this make it salient that understanding sometimes combines with behaviour in a less typical way, but the effectiveness of ostensibly defensive behaviour is also brought into attention.

Paradox research has always cared for the effectiveness of responses, but it may have converged prematurely on the effectiveness of a broad both/and category of response (Cunha and Putnam, 2019) and less ambiguous standards should be used to assess effectiveness (Putnam et al., 2016). More particular behavioural responses could be developed in purely behavioural terms (without cognitive or functional connotations, unless such characteristics are included in communication) to support more empirical investigation rather than 
conceptual assessment of their effectiveness. For example, researchers could distinguish between varieties of emotional recognition and integrated understanding expressed in communication, rather than presuming that any both/and response carries all benefits because it sometimes promotes the acceptance and integration of paradox. With and already recognised paradox, the communication of a specific, concrete and analytical integration of opposites could perhaps improve others' understanding better than other responses.

Using the three-phase framework allows more combinations of responses across the phases. For example, scholars may ask if the behavioural living with paradox works better based on a complex understanding, through embracement and a flexible attitude towards behaviour, or perhaps without even recognising paradox (El-Sawad et al., 2004). Responses of one phase may affect the responses of another, the behavioural responses affect the whole set of responses among active and passive others, and individuals may move from less to more complex responses, or the other way around, in more intricate ways than previously assumed. For example, if psychological tension results from often having to adhere behaviourally, although paradox is well-understood, does it force the individual to become anxious and adapt increasingly deteriorated ways of understanding paradox?

Knowledge of how individuals understand and possibly integrate paradox could inform processual models that consider the interaction of individual and organisational factors. For example, if individuals, despite process failures and context pressures, are able to retain a satisfactory understanding of paradox, couldn't they support behaviour that vitally contributes to 'bridging opposites' and breaking 'vicious cycles' (Abdallah et al., 2011; Jarzabkowski et al., 2013; Pradies et al., in press)? Further knowledge of individuals' sustained integration of paradox could foster the continual acknowledgement of paradox throughout the organisation.

The main limitation of this review is lack of attention to the context of individual 
responses to paradox. Both theoretical and empirical contexts have been overlooked. Future research may also want to address neglected characteristics of and insufficient discrimination between individual responses. For example, a few observations of individual integration of paradox have brought forth the instrumentality of links and whether links harm or sustain the opposites. More observations would help the definition and improve further identification of individual responses. A more complete framework would include other relevant factors that influence individual responses, and there is a need for a theoretical model that explain individual response to paradox.

Improving the individual 'ability to manage paradox' may prove important in years yet to come. As paradoxical demands intensify, because of greater diversity or changing and complex environments, individuals' responses to paradox become increasingly important (Smith and Lewis, 2011). In addition to sub-concepts such as the paradox mindset (MironSpektor et al., 2018; Spencer-Rodgers et al., 2009; Voronov and Yorks, 2015) and a repertoire of behaviours regarding paradox (Denison et al., 1995), this emerging concept should include appropriate recognition of various paradoxes and a repertoire of ways to understand paradoxes. It would also benefit from improved knowledge of the effectiveness of behavioural responses to achieving various goals within a range of organisational contexts.

Further knowledge of what constitutes a sufficient understanding of paradox for behaving effectively and responsibly appears to be important. We know that Eastern individuals, more easily than Westerners, embrace paradox and holistically locate it within broad and predefined integrations to act confidently (Chen, 2002; Peng and Nisbett, 1999). Western individuals plausibly prefer more local and specific integrations of paradox, which often fail because they are not fit to shifting local contexts. Further knowledge of general ways to demonstrably integrate paradox could provide a starting point for the continual reintegration of paradoxes in locally appropriate ways through analytical thinking as well as 
intuition across Western cultures. Knowledge of a greater diversity of individual responses would enhance paradox research's responsiveness to practitioners and responsibility to society.

\section{Acknowledgements}

The author would like to express gratitude to the editor Ruta Kazlauskaite and the three anonymous reviewers for constructive comments in developing this article. He also wants to thank all others that have commented on earlier versions. 


\section{References}

Abdallah, C., Denis, J. L. and Langley, A. (2011), "Having your cake and eating it too. Discourses of transcendence and their role in organizational change dynamics", Journal of Organizational Change Management, Vol. 24 No. 3, pp. 333-348. DOI:org/10.1108/09534811111132730.

Alvesson, M. and Sandberg, J. (2020), "The problematizing review: a counterpoint to Elsbach and Van Knippenberg's argument for integrative reviews", Journal of Management Studies, Vol. 57 No. 6, pp. 1290-1304. DOI:10.1111/joms.12582

Andriopoulos, C. and Lewis, M. W. (2009), "Exploitation-exploration tensions and organizational ambidexterity: managing paradoxes of innovation", Organization Science, Vol. 20 No. 4, pp. 696-717. DOI:10.1287/orsc.1080.0406.

Aoki, K. (2020), "The roles of material artifacts in managing the learning-performance paradox: the Kaizen case", Academy of Management Journal, Vol. 63 No.4, pp. 1266-1299. DOI:10.5465/amj.2017.0967.

Ban, Z. (2017), "Laboring under the cross: an analysis of discursive tension and identity in the context of a Chinese house church", Management Communication Quarterly, Vol. 31 No. 2, pp. 230-257. DOI:10.1177/0893318916680905.

Barge, J. K., Lee, M., Maddux, K., Nabring, R. and Townsend, B. (2008), "Managing dualities in planned change initiatives", Journal of Applied Communication Research, Vol. 36 No. 4, pp. 364-390. DOI:10.1080/00909880802129996.

Bartunek, J. M., Gordon, J. R. and Weathersby, R. P. (1983), "Developing “complicated" understanding in administrators", Academy of Management Review, Vol. 8 No. 2, pp. 273-284. DOI:10.5465/amr.1983.4284737. 
Bartunek, J. M., Walsh, K. and Lacey, C. A. (2000), "Dynamics and dilemmas of women leading women", Organization Science, Vol. 11 No. 6, pp. 589-610. DOI:10.1287/orsc.11.6.589.12531.

Baxter, L. A. and Montgomery, B. M. (1996), Relating. Dialogues \& Dialectics, The Guilford Press, New York.

Bednarek, R., Paroutis, S. and Sillince, J. (2017), "Transcendence through rhetorical practices: responding to paradox in the science sector", Organization Studies, Vol. 38 No. 1, pp. 77-101. DOI:10.1177/0170840616655486.

Beech, N., Burns, H., de Caestecker, L., MacIntosh, R. and MacLean, D. (2004), "Paradox as invitation to act in problematic change situations", Human Relations, Vol. 57 No. 10, pp. 1313-1332. DOI:10.1177/0018726704048357.

Berglund, J., Strannegaard, L. and Tillberg, U. (2004), "High-touch and high-techparadoxical narratives in a bank merger", Scandinavian Journal of Management, Vol. 20 No. 4, pp. 335-355. DOI:10.1016/j.scaman.2004.03.003.

Berti, M. and Simpson, A. V. (in press), "The dark side of organizational paradoxes: the dynamics of disempowerment", Academy of Management Review. DOI:org/10.5465/amr.2017.0208.

Calabretta, G., Gemser, G. and Wijnberg, N. M. (2017), "The interplay between intuition and rationality in strategic decision making: a paradox perspective", Organization Studies, Vol. 38 No. 3-4, pp. 365-401. DOI:10.1177/0170840616655483.

Canibano, A. (2019), "Workplace flexibility as a paradoxical phenomenon: exploring employee experiences", Human Relations, Vol. 72 No. 2, pp. 444-470. DOI:10.1177/0018726718769716. 
Carollo, L. and Guerci, M. (2018), "'Activists in a suit': paradoxes and metaphors in sustainability managers' identity work", Journal of Business Ethics, Vol. 148 No. 2, pp. 249-268. DOI:10.1007/s10551-017-3582-7.

Chen, M.-J. (2002), "Transcending paradox: the Chinese 'middle way' perspective", Asia Pacific Journal of Management, Vol. 19 No. 2-3, pp. 179-199. DOI:10.1023/A:1016235517735.

Child, C. (2020), "Whence paradox? Framing away the potential challenges of doing well by doing good in social enterprise organizations", Organization Studies, Vol. 41 No.8, pp. 1147-1167. DOI:10.1177/0170840619857467.

Cuganesan, S. (2017), "Identity paradoxes: how senior managers and employees negotiate similarity and distinctiveness tensions over time", Organization Studies, Vol. 38 No. 3-4, pp. 489-511. DOI:10.1177/0170840616655482.

Cunha, M. P. E. and Putnam, L. L. (2019), "Paradox theory and the paradox of success", Strategic Organization, Vol. 17 No. 1, pp. 95-106. DOI:10.1177/1476127017739536.

Denison, D. R., Hooijberg, R. and Quinn, R. E. (1995), "Paradox and performance: toward a theory of behavioral complexity in managerial leadership", Organization Science, Vol. 6 No. 5, pp. 524-540. DOI:10.1287/orsc.6.5.524.

Di Domenico, M. (2015), "Evolving museum identities and paradoxical response strategies to identity challenges and ambiguities: changing ethical understandings in the handling of human remains", Journal of Management Inquiry, Vol. 24 No. 3, pp. 300-317. DOI:10.1177/1056492615569885.

Eisenhardt, K. M., Furr, N. R. and Bingham, C. B. (2010), "Microfoundations of performance: balancing efficiency and flexibility in dynamic environments", Organization Science, Vol. 21 No. 6, pp. 1263-1273. DOI:10.1287/orsc.1100.0564. 
El-Sawad, A., Arnold, J. and Cohen, L. (2004), "'Doublethink': the prevalence and function of contradiction in accounts of organizational life", Human Relations, Vol. 57 No. 9, pp. 1179-1203. DOI:10.1177/0018726704047142.

Elsbach, K. D. and van Knippenberg, D. (2020), "Creating high-impact literature reviews: an argument for 'integrative reviews'", Journal of Management Studies, Vol. 57 No. 6, pp. 1277-1289. DOI:10.1111/joms.12581.

Fagerlin, W. P. and Wang, Y. Q. (2021), "Top managers' communication efforts as response to tensions in product innovation: an attention-based view", Baltic Journal of Management, Vol. 16 No. 1, pp. 21-45. DOI:10.1108/bjm-01-2020-0024.

Fairhurst, G. T., Cooren, F. and Cahill, D. J. (2002), "Discursiveness, contradiction and unintended consequences in successive downsizings", Management Communication Quarterly, Vol. 15 No. 4, pp. 501-540. DOI:10.1177/0893318902154001.

Fiol, C. M. (2002), "Capitalizing on paradox: the role of language in transforming organizational identities", Organization Science, Vol. 13 No. 6, pp. 653-666. DOI:10.1287/orsc.13.6.653.502.

Fredberg, T. (2014), "If I say it's complex, it bloody well will be: CEO strategies for managing paradox", Journal of Applied Behavioral Science, Vol. 50 No. 2, pp. 171188. DOI:10.1177/0021886314522859.

Gibbs, J. (2009), "Dialectics in a global software team: negotiating tensions across time, space, and culture", Human Relations, Vol. 62 No. 6, pp. 905-935. DOI:10.1177/0018726709104547.

Hahn, T. and Knight, E. (in press), "The ontology of organizational paradox: a quantum approach", Academy of Management Review. DOI:org/10.5465/amr.2018.0408.

Hahn, T., Preuss, L., Pinkse, J. and Figge, F. (2014), "Cognitive frames in corporate sustainability: managerial sensemaking with paradoxical and business case frames", 
Academy of Management Review, Vol. 39 No. 4, pp. 463-487.

DOI:10.5465/amr.2012.0341.

Hargrave, T. J. and Van de Ven, A. H. (2017), "Integrating dialectical and paradox perspectives on managing contradictions in organizations", Organization Studies, Vol. 38 No. 3-4, pp. 319-399. DOI:10.1177/0170840616640843.

Hoelscher, C. S. (2019), "Collaboration for strategic change: examining dialectical tensions in an interorganizational change effort", Management Communication Quarterly, Vol. 33 No. 3, pp. 329-362. DOI:10.1177/0893318919834340.

Howard, L. A. and Geist, P. (1995), "Ideological positioning in organizational-change - the dialectic of control in a merging organization", Communication Monographs, Vol. 62 No. 2, pp. 110-131. DOI:10.1080/03637759509376352.

Jarzabkowski, P., Le, J. K. and Van de Ven, A. H. (2013), "Responding to competing strategic demands: how organizing, belonging, and performing paradoxes coevolve", Strategic Organization, Vol. 11 No. 3, pp. 245-280. DOI:org/10.1177/1476127013481016.

Jian, G. W. (2007), "'Omega is a four-letter word": toward a tension-centered model of resistance to information and communication technologies", Communication Monographs, Vol. 74 No. 4, pp. 517-540. DOI:10.1080/03637750701716602.

Kan, M. M. and Parry, K. W. (2004), "Identifying paradox: a grounded theory of leadership in overcoming resistance to change", The Leadership Quarterly, Vol. 15 No. 4, pp. 467-491. DOI:10.1016/j.leaqua.2004.05.003.

Knight, E. and Harvey, W. (2015), "Managing exploration and exploitation paradoxes in creative organisations", Management Decision, Vol. 53 No. 4, pp. 809-827. DOI:10.1108/md-03-2014-0124. 
Knight, E. and Paroutis, S. (2017), "Becoming salient: the TMT leader's role in shaping the interpretive context of paradoxical tensions", Organization Studies, Vol. 38 No. 3-4, pp. 403-432. DOI:10.1177/0170840616640844.

Lewis, M. W. (2000), "Exploring paradox: toward a more comprehensive guide", Academy of Management Review, Vol. 25 No. 4, pp. 760-776. DOI:10.5465/amr.2000.3707712.

Lüscher, L. S. and Lewis, M. W. (2008), "Organizational change and managerial sensemaking: working through paradox", Academy of Management Journal, Vol. 51 No. 2, pp. 221-240. DOI:10.5465/amj.2008.31767217.

McNamee, L. G. and Peterson, B. L. (2014), "Reconciling "third space/place": toward a complementary dialectical understanding of volunteer management", Management Communication Quarterly, Vol. 28 No. 2, pp. 214-243.

DOI: $10.1177 / 0893318914525472$.

Mickel, A. E. and Dallimore, E. J. (2009), "Life-quality decisions: tension-management strategies used by individuals when making tradeoffs", Human Relations, Vol. 62 No. 5, pp. 627-668. DOI:10.1177/0018726709103453.

Miron-Spektor, E., Ingram, A., Keller, J., Smith, W. K. and Lewis, M. W. (2018), "Microfoundations of organizational paradox: the problem is how we think about the problem", Academy of Management Journal, Vol. 61 No. 1, pp. 26-45. DOI:10.5465/amj.2016.0594.

Murnighan, J. K. and Conlon, D. E. (1991), "The dynamics of intense work-a study of British string-quartets", Administrative Science Quarterly, Vol. 36 No. 2, pp. 165186.

Olsen, T. H. and Solstad, E. (2020), "Changes in the power balance of institutional logics: middle managers' responses", Journal of Management \& Organization, Vol. 26 No. 4, pp. 571-584. DOI:10.1017/jmo.2017.72. 
Pache, A.-C. and Santos, F. (2013), "Embedded in hybrid contexts: how individuals in organizations respond to competing institutional logics", Research in the Sociology of Organizations, Vol. 39B, pp. 3-35.

Pamphile, V. D. (in press), "Paradox peers: a relational approach to navigating a businsssociety paradox", Academy of Management Journal. DOI:org/10.5465/amj.2019.0616.

Papachroni, A., Heracleous, L. and Paroutis, S. (2016), "In pursuit of ambidexterity: managerial reactions to innovation-efficiency tensions", Human Relations, Vol. 69 No. 9, pp. 1791-1822. DOI:10.1177/0018726715625343.

Peng, K. and Nisbett, R. E. (1999), "Culture, dialectics, and reasoning about contradiction", American Psychologist, Vol. 54 No. 9, pp. 741-754. DOI:10.1037/0003066X.54.9.741.

Poole, M. S. and Van de Ven, A. H. (1989), "Using paradox to build management and organization theories", Academy of Management Review, Vol. 14 No. 4, pp. 562-578. DOI:10.5465/amr.1989.4308389.

Pradies, C., Tunarosa, A. and Courtois, J. (in press), "From vicious to virtuous paradox dynamics: the social-symbolic work of supporting actors", Organization Studies. DOI:org/10.1177/0170840620907200.

Putnam, L. L., Fairhurst, G. T. and Banghart, S. (2016), "Contradictions, dialectics, and paradoxes in organizations: a constitutive approach", Academy of Management Annals, Vol. 10 No. 1, pp. 65-171. DOI:10.1080/19416520.2016.1162421.

Schad, J., Lewis, M. W., Raisch, S. and Smith, W. K. (2016), "Paradox research in management science: looking back to move forward", Academy of Management Annals, Vol. 10 No. 1, pp. 5-64. DOI:10.1080/19416520.2016.1162422. 
Seo, M.-G., Putnam, L. and Bartunek, J. M. (2004), "Dualities and tensions of planned organizational change", Poole, M. S. and Van de Ven, A. H. (Ed.s), Handbook of Organizational Change and Innovation. Oxford University Press, Oxford, pp. 73107.

Sharma, G. and Bansal, P. (2017), "Partners for good: how business and NGOs engage the commercial-social paradox", Organization Studies, Vol. 38 No. 3-4, pp. 341-364. DOI: $10.1177 / 0170840616683739$.

Sirris, S. (2019), "Coherent identities and roles? Hybrid professional managers' prioritizing of coexisting institutional logics in differing contexts", Scandinavian Journal of Management, Vol. 35 No. 4, pp. 1-12. DOI:10.1016/j.scaman.2019.101063.

Smets, M., Jarzabkowski, P., Burke, G. T. and Spee, P. (2015), "Reinsurance trading in Lloyd's of London: balancing conflicting-yet-complementary logics in practice", Academy of Management Journal, Vol. 58 No. 3, pp. 932-970.

DOI:10.5465/amj.2012.0638.

Smith, K. K. and Berg, D. N. (1987), Paradoxes of Group Life. Understanding Conflict, Paralysis, and Movement in Group Dynamics, Jossey-Bass Publishers, San Francisco, CA.

Smith, W. K. (2014), "Dynamic decision making: a model of senior leaders managing strategic paradoxes", Academy of Management Journal, Vol. 57 No. 6, pp. 15921623. DOI:10.5465/amj.2011.0932.

Smith, W. K. and Besharov, M. L. (2017), "Bowing before dual Gods: how structured flexibility sustains organizational hybridity", Administrative Science Quarterly, Vol. 64 No. 1, pp. 1-44. DOI:10.1177/0001839217750826. 
Smith, W. K. and Lewis, M. W. (2011), "Toward a theory of paradox: a dynamic equilibrium model of organizing", Academy of Management Review, Vol. 36 No. 2, pp. 381-403. DOI:10.5465/amr.2009.0223.

Smith, W. K. and Tushman, M. L. (2005), "Managing strategic contradictions: a top management model for managing innovation streams", Organization Science, Vol. 16 No. 5, pp. 522-536. DOI:10.1287/orsc.1050.0134.

Solebello, N., Tschirhart, M. and Leiter, J. (2016), "The paradox of inclusion and exclusion in membership associations", Human Relations, Vol. 69 No. 2, pp. 439-460. DOI:10.1177/0018726715590166.

Spencer-Rodgers, J., Boucher, H. C., Mori, S. C., Wang, L. and Peng, K. P. (2009), "The dialectical self-concept: contradiction, change, and holism in East Asian cultures", Personality and Social Psychology Bulletin, Vol. 35 No. 1, pp. 29-44.

DOI:10.1177/0146167208325772.

Stadtler, L. and Van Wassenhove, L. N. (2016), "Coopetition as a paradox: integrative approaches in a multi-company, cross-sector partnership", Organization Studies, Vol. 37 No. 5, pp. 655-685. DOI:10.1177/0170840615622066.

Stohl, C. and Cheney, G. (2001), "Participatory processes / paradoxical practices. Communication and the dilemmas of organizational democracy", Management Communication Quarterly, Vol. 14 No. 3, pp. 349-407. DOI:10.1177/0893318901143001.

Tracy, S. J. (2004), "Dialectic, contradiction, or double bind? Analyzing and theorizing employee reactions to organizational tension", Journal of Applied Communication Research, Vol. 32 No. 2, pp. 119-146. DOI:10.1080/0090988042000210025. 
Tuckermann, H. (2019), "Visibilizing and invisibilizing paradox: a process study of interactions in a hospital executive board", Organization Studies, Vol. 40 No. 12, pp. 1851-1872. DOI:10.1177/0170840618800100.

Vallaster, C., Maon, F., Lindgreen, A. and Vanhamme, J. (2021), "Serving multiple masters: the role of micro-foundations of dynamic capabilities in addressing tensions in forprofit hybrid organizations", Organization Studies, Vol. 42 No. 6, pp. 911-947. DOI:10.1177/0170840619856034

Vermaak, H. (2012), "Facilitating local ownership through paradoxical interventions", Journal of Applied Behavioral Science, Vol. 48 No. 2, pp. 225-247. DOI:10.1177/0021886312438860.

Voronov, M. and Yorks, L. (2015), "'Did you notice that?" Theorizing differences in the capacity to apprehend institutional contradictions", Academy of Management Review, Vol. 40 No. 4, pp. 563-586. DOI:10.5465/amr.2013.0152.

Wood, J. T. and Conrad, C. (1983), "Paradox in the experiences of professional women", The Western Journal of Speech Communication, Vol. 47 No. Fall 1983, pp. 305-322. DOI:10.1080/10570318309374128.

Zimmermann, A., Raisch, S. and Cardinal, L. B. (2018), "Managing persistent tensions on the frontline: a configurational perspective on ambidexterity", Journal of Management Studies, Vol. 55 No. 5, pp. 739-769. DOI:10.1111/joms.12311. 
Figure 1. Initial frame of individual responses to a paradox.

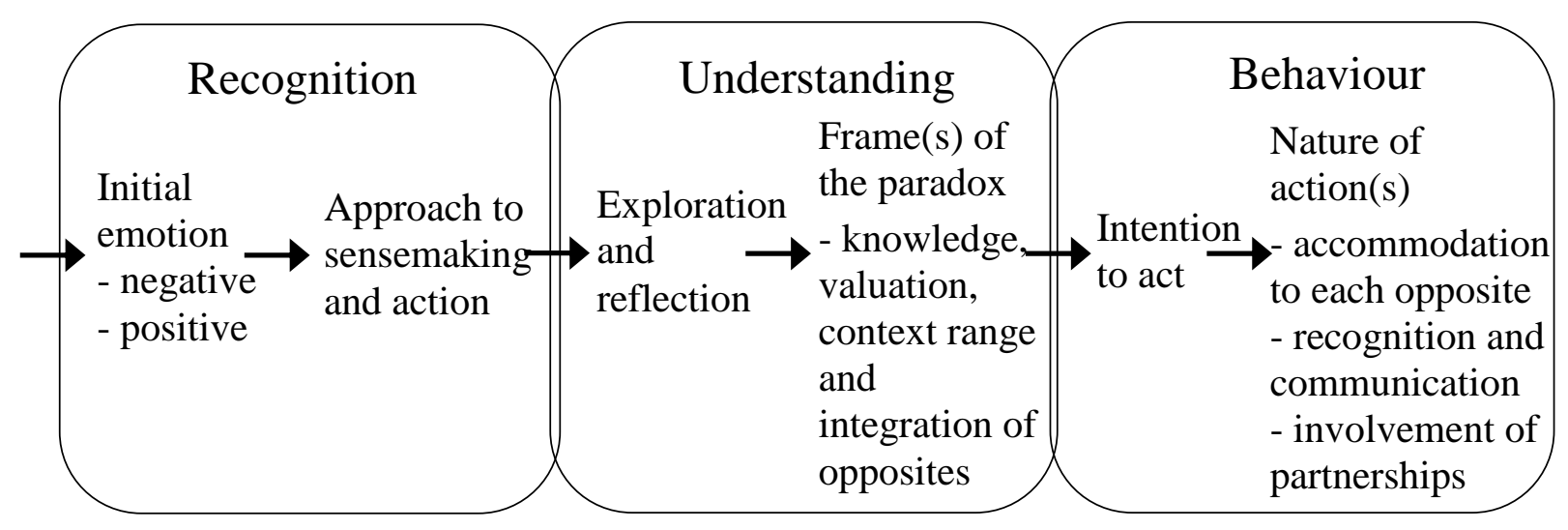


Table 1. Literature selected for review.

\begin{tabular}{|c|c|c|c|}
\hline 'Paradox lens' studies & & Communication and critical theory & \\
\hline Lüscher and Lewis (2008) & AMJ & Wood and Conrad (1983) & WJSC \\
\hline Andriopoulos and Lewis & OSc & Howard and Geist (1995) & $\mathrm{CM}$ \\
\hline (2009) & & Fairhurst et al. (2002) & MCQ \\
\hline Smith (2014) & AMJ & Berglund et al. (2004) & SJM \\
\hline Bednarek et al. (2017) & OS & Tracy (2004) & JACR \\
\hline Calabretta et al. (2017) & OS & Jian (2007) & $\mathrm{CM}$ \\
\hline Cuganesan (2017) & OS & Gibbs (2009) & HR \\
\hline Knight and Paroutis (2017) & OS & McNamee and Peterson (2014) & MCQ \\
\hline Pradies et al. (in press) & OS & Hoelscher (2019) & MCQ \\
\hline Mostly empirically based & & Particular perspectives & \\
\hline Murnighan and Conlon (1991) & ASQ & Bartunek et al. (2000) & OSc \\
\hline Seo et al. (2004) & Book Ch & (empowerment) & \\
\hline Kan and Parry (2004) & LQ & Beech et al. (2004) ('serious play') & HR \\
\hline Barge et al. (2008) & JACR & El-Sawad et al. (2004) & HR \\
\hline Mickel and Dallimore (2009) & HR & ('doublethink') & \\
\hline Fredberg (2014) & $\mathrm{JABS}$ & Vermaak (2012) (helping & JABS \\
\hline Knight and Harvey (2015) & MD & relationship) & \\
\hline Papachroni et al. (2016) & HR & Di Domenico (2015) (museum & JMI \\
\hline Solebello et al. (2016) & HR & identity) & \\
\hline Stadtler and Wassenhove & OS & Canibano (2019) (psych. contract) & HR \\
\hline$(2016)$ & & Tuckerman (2019) (social systems) & OS \\
\hline Carollo and Guerci (2018) & JBE & Child (2020) (sensemaking) & OS \\
\hline Zimmerman et al. (2018) & JMS & Fagerlin and Wang (2021) & BJM \\
\hline Aoki (2020) & AMJ & (attention) & \\
\hline Pamphile (in press) & AMJ & Frameworks of individual responses & \\
\hline Inst. complexity and hybrid org. & & Poole and Van de Ven (1989) & AMR \\
\hline Smets et al. (2015) & AMJ & Baxter and Montgomery (1996) & Book \\
\hline Smith and Besharov (2017 & ASQ & Stohl and Cheeney (2001) & MCQ \\
\hline Sirris (2019) & SJM & Pache and Santos (2013) & $\mathrm{RSO}$ \\
\hline Olsen and Solstad (2020) & JMO & Schad et al. (2016) & AMA \\
\hline Vallaster et al. (in press) & OS & Putnam et al. (2016) & AMA \\
\hline
\end{tabular}

The abbreviations refer to: AMA=Academy of Management Annals, AMJ=Academy of Management Journal, $\mathrm{AMR}=$ Academy of Management Review, ASQ= Administrative Science Quarterly, BJM=Baltic Journal of Management, $\mathrm{CM}=$ Communication Monographs, $\mathrm{HR}=$ Human Relations, JABS=Journal of Applied Behavioural Science, JACR=Journal of Applied Communication Research, JBE=Journal of Business Ethics, JMI=Journal of Management Inquiry, JMO=Journal of Management \& Organization, LQ=The Leadership Quarterly, $\mathrm{MCQ}=$ Management Communication Quarterly, $\mathrm{MD}=$ Management Decision, $\mathrm{OS}=$ Organization Studies, OSc=Organization Science, RSO=Research in the Sociology of Organizations, SJM=Scandinavian Journal of Management, WJSC $=$ Western Journal of Speech Communication 
Figure 2. Individual responses to paradox within three phases.

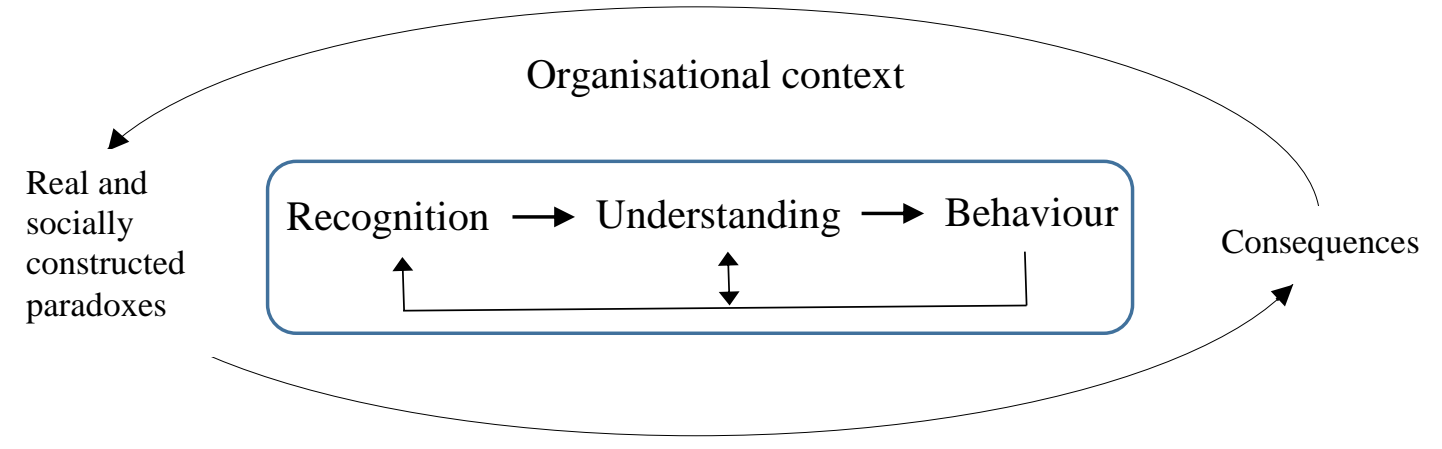

\begin{tabular}{|c|c|c|c|}
\hline & Recognition & Understanding & Behaviour \\
\hline \multirow{5}{*}{$\begin{array}{l}\mathrm{C} \\
\mathrm{O} \\
\mathrm{M} \\
\mathrm{P} \\
\mathrm{L} \\
\mathrm{E} \\
\mathrm{X} \\
\mathrm{I} \\
\mathrm{T} \\
\mathrm{Y}\end{array}$} & Denial & Selection & $\begin{array}{l}\text { Avoidance } \\
\text { Adherence }\end{array}$ \\
\hline & $\begin{array}{l}\text { Neglect } \\
\text { Disorientation } \\
\text { Resistance }\end{array}$ & Separation & Vacillation \\
\hline & Embracement & $\begin{array}{l}\text { Prioritisation } \\
\text { Balance }\end{array}$ & $\begin{array}{l}\text { Advocacy } \\
\text { Reflective } \\
\text { vacillation }\end{array}$ \\
\hline & & $\begin{array}{l}\text { Seeking } \\
\text { integration } \\
\text { Simple } \\
\text { complementarity }\end{array}$ & $\begin{array}{l}\text { Balancing practices } \\
\text { Bounded } \\
\text { communication }\end{array}$ \\
\hline & Acceptance & $\begin{array}{l}\text { Synthesis } \\
\text { Transcendence }\end{array}$ & $\begin{array}{l}\text { Symbolic integration } \\
\text { Living with paradox } \\
\text { Shaping the context }\end{array}$ \\
\hline
\end{tabular}


Table 2. Some patterns of responses across the three phases.

\begin{tabular}{|c|c|c|c|}
\hline Recognition & Understanding & Behaviour & Literature \\
\hline \multicolumn{4}{|c|}{ The emotion of recognition determines (understanding and) behaviour } \\
\hline $\begin{array}{l}\text { Denial } \\
\text { (anxiety) }\end{array}$ & & Avoidance & \multirow{3}{*}{$\begin{array}{l}\text { Murnighan and Conlon } \\
\text { (1991) } \\
\text { Bartunek et al. (2000) } \\
\text { Beech } \text { et al. (2004) } \\
\text { Lüscher and Lewis } \\
\text { (2008) } \\
\text { Pamphile (in press) } \\
\text { Pradies et al. (in press) }\end{array}$} \\
\hline $\begin{array}{l}\text { Embracement } \\
\text { (desire) }\end{array}$ & $\begin{array}{l}\text { Prioritisation } \\
\text { Balance }\end{array}$ & $\begin{array}{l}\text { Vacillation } \\
\text { Living with paradox }\end{array}$ & \\
\hline $\begin{array}{l}\text { Acceptance } \\
\text { (equanimity, } \\
\text { ambivalence) }\end{array}$ & $\begin{array}{l}\text { Balance and } \\
\text { (seeking) } \\
\text { integration }\end{array}$ & Living with paradox & \\
\hline \multicolumn{4}{|c|}{ Behaviour and understanding at the same level of complexity } \\
\hline & Selection & Adherence & \multirow{5}{*}{$\begin{array}{l}\text { Barge et al. (2008) } \\
\text { Gibbs (2009) } \\
\text { Papachroni et al. }(2016) \\
\text { Cuganesan (2017) } \\
\text { Knight and Paroutis } \\
\text { (2017) } \\
\text { Canibano (2019) } \\
\text { Fagerlin and Wang } \\
(2021)\end{array}$} \\
\hline & Separation & $\begin{array}{l}\text { Adherence, } \\
\text { Vacillation }\end{array}$ & \\
\hline & Prioritisation & $\begin{array}{l}\text { Vacillation, } \\
\text { Advocacy }\end{array}$ & \\
\hline & Balance & $\begin{array}{l}\text { Vacillation, } \\
\text { Reflective vacillation }\end{array}$ & \\
\hline & $\begin{array}{l}\text { Seeking } \\
\text { integration, } \\
\text { Integration }\end{array}$ & $\begin{array}{l}\text { Reflective vacillation, } \\
\text { Balancing practices, } \\
\text { Bounded } \\
\text { communication, } \\
\text { Living with paradox, } \\
\text { Shaping the context }\end{array}$ & \\
\hline \multicolumn{4}{|c|}{ Perhaps surprising combinations of understanding and behaviour } \\
\hline & $\begin{array}{l}\text { Balance and } \\
\text { seeking } \\
\text { integration }\end{array}$ & $\begin{array}{l}\text { Avoidance, } \\
\text { Adherence }\end{array}$ & $\begin{array}{l}\text { Jian (2007) } \\
\text { Tuckerman (2019) } \\
\text { Aoki (2020) }\end{array}$ \\
\hline
\end{tabular}

